\title{
MULHER, MÃE E... TRABALHADORA DE ENFERMAGEM
}

\section{BEING A WOMAN, MOTHER AND NURSING PROFESSIONAL}

Thelma Spindola *

SPÍNDOLA, T. Mulher, mãe e...trabalhadora de enfermagem. Rev.Esc.Enf.USP, v.34, n.4, p. 354-61, dez. 2000.

\section{RESUMO}

Este trabalho se propõe a desvelar o significado para as profissionais de enfermagem do fenômeno "ser mulher ,mãe $e$ trabalhadora de enfermagem" , através de um estudo qualitativo, com abordagem fenomenológica. Os sujeitos da pesquisa foram mulheres atuantes num hospital geral público do município do Rio de Janeiro. A análise dos depoimentos permitiu a identificação de unidades de significado evidenciando que as depoentes acham complicado conciliar casa, trabalho e filhos, sendo mais difícil quando os filhos são pequenos. Assim, pudemos desvelar das falas que ser mulher, mãe e profissional é desafiador para essas mulheres que, continuamente, sentem suas capacidades sendo testadas.

PALAVRAS-CHAVE: Mulher. Mãe. Enfermeiras.

\begin{abstract}
The purpose of this paper is to reveal the meaning of the phenomenon "being a woman, mother and nursing professional" to nursing professionals through a qualitative study and a phenomenological approach. Women who work at a public hospital in the city of Rio de Janeiro are the subjects of this research. The analysis of their statements allowed the identification of meanings that made it clear that women consider it complicated to conciliate home, work and kids, especially when they are small. Thus, what can be inferred from their statements is that being a woman, mother and professional is a challenge for them, who constantly have their abilities tested.
\end{abstract}

KEYWORDS: Woman. Mother. Nurses.

\section{INTRODUÇÃO}

Há alguns anos venho convivendo com esta realidade: ser mulher, mãe e trabalhadora de enfermagem.

Ser mulher foi percebido gradativamente, pelo próprio amadurecimento. A distinção entre o que era ser mulher e ser homem foi explicitada no convivio com a família, em função do que era permitido / negado à mulher. Tendo irmãos de ambos os sexos, podia perceber o que deveria ser um "comportamento desejável" / "aceitável", os atributos essenciais a uma "boa mulher", e a própria "diferença" entre os sexos. Esta conotação é esclarecida por FONSECA (1997) ao afirmar que:
Ser mulher, em nossa sociedade, significa estar inserida, enquanto agente social, num sistema cujo conteúdo é pautado por subordinações. Nascer mulher manifesta-se como um ato primeiro e involuntário de inscrição em relações marcadas pelo poder da dominação masculina.

Cresci convivendo com as diferenças mas, apesar de acatar as decisões familiares, ansiava por um mundo diferente, por novos horizontes, pela obtenção de conquistas distintas das que observava no cotidiano das mulheres da minha família. E, na

* Enf ${ }^{\sharp}$ do „Hospital Universitário Gafrée e Guinle da Universidade do Rio de Janeiro (UNI-RIO), Mestre em Enfermagem, Professora Assistente da Faculdade de Enfermagem da Universidade do Estado do Rio de Janeiro (UERJ), Doutoranda da EEAN-UFRJ. E.mail: spindola@centroin.com.br 
busca de novos conhecimentos, vislumbrei a oportunidade de assumir uma profissão para, então, criar possibilidades de trabalho que me levariam à minha independência pessoal e econômica, fundamentais para atingir meus objetivos.

Inicialmente, fiz um Curso de Instrumentação Cirúrgica que me permitiu estagiar em Hospital Geral Público no Municipio do Rio de Janeiro. Em contato com profissionais de saúde da referida Instituição, consegui meu primeiro emprego como auxiliar no consultório de um médico cuja especialidade era Ginecologia / Obstetrícia. Quando necessário, atuava, também, como Instrumentadora em eventuais cirurgias. Permaneci pouco tempo nesta situação, pois continuava estudando com vistas ao concurso Vestibular. Ao realizá-lo, fui aprovada e selecionada para a carreira de Enfermagem.

Favorecida pela proximidade aos profissionais da área de Saúde em meu cotidiano e pela aptidão por esta modalidade de trabalho, costumava observar a atuação dos profissionais das mais distintas áreas, identificando-me com a Enfermagem. Ser Enfermeira apresentava-se para mim como a oportunidade de realização enquanto Mulher Trabalhadora, assumindo uma profissão, escolhendo o próprio caminhar, escrevendo a própria história...

A Enfermagem, enquanto opção profissional, tem sido associada por diversos autores, à devoção e amor ao próximo e, atualmente, também à possibilidade de inserção num mercado de trabalho em expansão. Cada vez mais as enfermeiras vêm ampliando suas áreas de atuação, demonstrando competência para além do cuidar.

Ao longo da minha vida profissional superei os mais diversos desafios vivenciando sentimentos de alegria e realização pelas conquistas, como também de frustração e impotência diante das condições de trabalho oferecidas pelas Instituições públicas de saúde que vêm atravessando, ultimamente, um grave desequilíbrio econômicoestrutural.

Passaram-se os anos ... e eis que me tornei Mãe! Um momento especial, mágico, repleto de alegria, realização, de completa doação à um Ser pequenino. Vivendo o Ser Mulher em sua plenitude pela maternidade, surgiu o impasse: como conciliar o Ser Mãe, Ser Mulher e Ser Enfermeira? A maternidade é um evento importante na vida de toda mulher. É quando os diversos papéis por ela assumidos (Mãe, Mulher e Profissional) entram em conflito, ora prevalecendo um ou outro, obrigando-a a "conciliá-los". A partir daí, surgem os momentos dificeis, plenos de dúvidas, questionamentos e muitas solicitações. O Ser Mãe é um papel que pode superar os demais, enquanto o de Ser Mulher é continuamente testado. Este é um daqueles momentos cruciais, marcantes para as mulheres que têm filhos e, em especial, para as que exercem uma atividade profissional!

Instigada pela trama de vida diária com meus múltiplos papéis, já com a sensibilidade aguçada, percebi que este momento único é compartilhado por outras mulheres que vivenciam a mesma problemática, independentemente da categoria profissional à qual pertençam. Todavia, pela proximidade e identificação com as trabalhadoras de enfermagem,comecei a dialogar e trocar experiências com elas acerca desta realidade. A cada encontro era possivel constatar que todas sentiam, no seu dia-adia, alegria, frustração, decepção, preocupação, satisfação ou insatisfação, tudo em decorrência dos múltiplos papéis assumidos.

A preocupação com estas mulheres e sua visão de mundo há muito me inquieta. Na tentativa de compreender o fenômeno "Ser Mulher, Mãe e Trabalhadora de Enfermagem", optei por realizar um estudo que clarificasse a problemática e facilitasse sua compreensão, acreditando que somente aquelas que vivenciam tais papéis poderiam esclarecer as peculiaridades de cada situação. Assim, este estudo pretende compreender o significado de Ser Mulher, Mãe, e Trabalhadora de Enfermagem, sob a ótica daquelas que vivem esta realidade acreditando que, a partir do desvelar deste fenômeno, será possivel compreender melhor esta parcela da população feminina.

\section{O SER MULHER, MÃE TRABALHADORA DE ENFERMAGEM}

A diferença entre os sexos sempre existiu, sempre esteve presente desde o início dos tempos. Não apenas no sentido biológico, mas principalmente no social. No entender de (FONSECA, 1997),

\section{(...) o sexo social e historicamente construido é produto das relações sociais entre homens e mulheres e deve ser entendido como elemento constitutivo destas mesmas relações nas quais as diferenças são apresentadas como naturais e inquestionáveis ao contrário, a análise mais profunda de tais relações revela condiçóes extremamente desiguais de exercicio de poder, onde as mulheres vem ocupando posições subalternas e secundárias em relação aos homens.}

Assim sendo, esta condição de desigualdade tem se perpetuado há anos. Lembrando Calvo apud MASSI (1992), vemos que "(...) relega-se à mulher o 
familiar, o individual, o privado , o pessoal e o doméstico, desvalorizando-o em certos aspectos e também fazendo com que este conjunto se mostre como algo separado da esfera social". Por outro lado , MASSI (1992) também reforça a idéia de que cabe à mulher a transmissão da ideologia de sua classe social, mesmo sem dar-se conta deste papel. Então ela participa ativamente da educação dos filhos, reprime sua sexualidade, perpetuando sua opressão e desvalorização e contribuindo para a formação de homens e mulheres que, futuramente, tomarão por base as informações recebidas e os valores e conceitos assimilados em sua educação familiar. Decorre daí que a mulher, não tendo clara consciência do seu importante papel como agente transmissor de conceitos e ideologias, acaba não (re)conhecendo seu verdadeiro papel, fazendo-se desvalorizar.

Após a Revolução Industrial, a mulher deixou o espaço privado (casa, marido, filhos) e passou a ocupar o espaço público, assumindo uma profissão. Para OLIVEIRA e PEREIRA (1997), nesta ocasião a mulher deixou de ser esposa e mãe somente, para ser, também, operária, enfermeira, professora, e com o passar do tempo, arquiteta, juíza, motorista de ônibus e outras. A participação cada vez maior da mulher no mercado de trabalho, lembra Barañano apud SCHIRMER (1997), compondo a população economicamente ativa e no emprego assalariado, é uma constante desde os anos $70 \mathrm{em}$ todos os países ocidentais.

No Brasil , refere SCHIRMER (1997), nota-se um crescimento da população feminina no mercado de trabalho desde aquela época, cada vez mais intenso e diversificado, não mostrando nenhuma tendência de retrocesso apesar das crises econômicas que assolaram o país a partir dos anos 80. Em 1990, indica a referida autora, haviam mais de 22,9 milhões de trabalhadoras constituindo cerca de $40 \%$ do conjunto da força de trabalho brasileira.

A inserção da mulher no mercado de trabalho provocou alterações significativas em seu cotidiano. SARTI (1997) reforça este pensamento ao afirmar que esse processo social adquiriu dimensão estrutural no mundo contemporâneo sendo, junto com o desenvolvimento de métodos anticoncepcionais mais seguros, um dos fatores que mais radicalmente contribuiu para a redefinição do lugar social da mulher, com conseqüências decisivas nas relações familiares que, gradativamente, foram modificadas em sua organização, na divisão de tarefas domésticas, na educação dos filhos... SARTI (1997) lembra ainda que a inserção feminina no "mundo" do trabalho, nas duas últimas décadas, não teve o mesmo impacto para todas as mulheres e cita que:

O trabalho remunerado implicou uma mudança significativa no modo de vida das mulheres com qualificação profissional, que graças não só a expansão do mercado de trabalho mas também do sistema educacional brasileiro, tiveram condições de romper com o padrão de divisão sexual da geração de suas mães, que "não trabalhavam" (leia-se remuneradamente), alterando, assim, a organização de sua vida familiar.

Na opção da mulher pelo "mundo" do trabalho, refere MOREIRA (1999), deu-se a busca por carreiras que se aproximassem das características femininas. Assim, afirma que "(...) a saída de casa deu-se através de profissões tais como enfermagem e magistério, onde a mulher aparece com funções de cuidado e ensino remetidas ao universo familiar". O mesmo sentido é lembrado por Ehrenreich e English apud WALDOW (1996) destacando que, no século XIX, "(...) enquanto algumas mulheres profissionalizavam os papéis domésticos das mulheres,outras domesticavam papéis profissionais, como a enfermagem, a educação e mais tarde, o serviço social." Ressaltam, ainda, que a Enfermagem desempenha um papel social no sistema de saúde semelhante aos de mãe e esposa.

De acordo com esta concepção, a mulher buscou de início atividades compativeis com suas habilidades (ou áreas para as quais tivessem maior aptidão). Assim, assumiram profissões tais como: professora e enfermeira, para as quais julgavam-se mais preparadas, como também porque eram as mais aceitas pela sociedade. Neste sentido, AVENDAÑO, GRAU e YUS (1997) esclarecem que "(...) o fenômeno de "femininização da enfermagem" ou de encaminhamento seletivo das mulheres para essa atividade foi explicado como uma resultante do processo de tipificação sexual dos papéis considerados "apropriados" (cultural e socialmente), transmitido através do processo de socialização. Nesta perspectiva, reconhecem a enfermagem "(...) como um prolongamento das atividades de cuidado e atenção da saúde que as mulheres têm assumido historicamente em relação às suas famílias e a comunidade."

Quanto à enfermagem, como opção profissional, SOBRAL (1994) refere ser uma profissão de mulheres, do gênero feminino, que envolve representações sociais inerentes às "características" da mulher ideal numa sociedade ainda dominada pelos homens, tais como: submissão, abnegação, disciplina, pureza, humildade e "domesticidade". Reforçando este pensamento, MOREIRA (1999) lembra que a enfermagem, como o magistério, é caracterizada como uma profissão de mulheres, profissão esta que, no mundo público, representava uma extensão do lar, de um feminino dócil, que cuida, nutre e educa. Assim sendo, ressalta (SOBRAL, 1994): 
Foi só deslocar uma cultura pronta, que era da mulher, mãe e esposa no espaço privado cuidando da casa, dos filhos e do marido, para o espaço público: substituise, neutralizando, a casa pelo hospital, os filhos pelos sujeitos do cuidado, o povo e o marido pelo médico.

Avaliando esta questão por outro ângulo, podemos afirmar, então, ser "compreensivel" porque a enfermagem é percebida por alguns como profissão desvalorizada ou pouco reconhecida; ou até mesmo, porque este "reconhecimento" e "valor" ficam tão a nivel pessoal para os profissionais da área, uma vez que, por ser uma profissão essencialmente feminina traz em seu bojo as "características" e talvez as próprias "dificuldades" do gênero, em uma sociedade patriarcal e machista como a nossa.

A relação Mulher-Trabalho-Família nunca foi harmoniosa. Os conflitos sempre estiveram presentes. Na relação familiar, com a inserção da mulher no mercado de trabalho os "papéis domésticos" modificaram-se: o que antes era atribuição exclusiva da mulher passou, então, a ser "dividido" ou "compartilhado" pelo companheiro. Ocorreram modificações na própria estrutura da vida doméstica, como a incorporação, no domicílio, de recursos tecnológicos que facilitassem os afazeres domésticos, a escolha de creches para guarda das crianças enquanto os pais estivessem trabalhando... enfim, toda a configuração da família modificou-se.

Surgiram alterações na legislação trabalhista para atender as necessidades deste contingente profissional que, apesar de não serem ideais, garantiam à mulher a licença maternidade e a licença para amamentação. Cabe esclarecer que este direito nem sempre é observado, mas é assegurado às trabalhadoras das instituições municipais e estaduais do Rio de Janeiro. Todavia, ainda hoje a opressão familiar, e também a das próprias empresas afastam muitas mulheres do mercado de trabalho após o nascimento dos filhos, ou impedem seu (re)ingresso quando estes já existem, devido a dificuldade de conciliação de horários (atividades de MãeTrabalhadora). Aquelas que resistem a esses transtornos e atuam profissionalmente, fazem-no com grande sacrificio, sentimentos de culpa pelas ausências, sensações de perdas...

Para SCHIRMER (1997) o fator que mais interfere negativamente na participação feminina no mercado de trabalho é a presença dos filhos:

A responsabilidade pela guarda, cuidado e educação dos filhos na familia e a falta de equipamentos coletivos, como creches, limitam a saida das mulheres para o mercado de trabalho remunerado, sobretudo se os rendimentos obtidos são insuficientes para cobrir custos com formas remuneradas de cuidado infantil.
Assim sendo , lembra FONSECA (1997), a vida de trabalho desenvolvido na esfera pública mostrase impregnada pela crença que:

(...) do lado da gestão, pode assumir feições de justificativa à divisão social $e$ técnica do trabalho ( trabalho de homem $X$ trabalho de mulher), aos niveis de remuneração, bem como às escassas oportunidades de qualificação e de carreira concedidas às mulheres que são percebidas como recursos humanos cuja tendência é sempre a de voltar para casa e sobre os quais não compensa maiores investimentos.

Deste modo, permanecer no mercado de trabalho, conciliar a vida pública com a vida privada, atender às diversas solicitações dos "mundos"diferenciados tornase um grande desafio para essas mulheres.

\section{METODOLOGIA}

Estudo descritivo, em abordagem qualitativa, seguindo a trajetória fenomenológica com a finalidade de compreender o fenômeno ser mulher, mãe e trabalhadora de enfermagem sob a ótica daquelas que convivem com esta realidade. A abordagem fenomenológica cria possibilidades de compreender o fenômeno conforme se apresenta àqueles que vivenciam a situação preocupando-se com a sua essência.

O significado de ser mulher, mãe e trabalhadora de enfermagem deverá ser buscado nas respostas das mulheres que vivenciam em seu cotidiano esta experiência. Através de seus depoimentos será possivel desvelar e apreender a essência do fenômeno. Então, para facilitar o discurso e a elaboração das descrições, elaborou-se a questão orientadora: "O que significa para você ser mulher, mãe e trabalhadora de enfermagem?"

\section{Cenário do Estudo}

O estudo foi realizado em uma Instituição Geral Pública do Municipio do Rio de Janeiro. A coleta dos depoimentos ocorreu nos meses de dezembro de 1998 e janeiro de 1999 e os sujeitos foram mulheres, profissionais de enfermagem (enfermeiras, técnicas de enfermagem e auxiliares de enfermagem) atuantes nas mais diversas especialidades e que tivessem filhos.

\section{Obtenção das falas}

$\mathrm{Na}$ qualidade de enfermeira e pesquisadora atuante na Instituição, aproximei-me das 
profissionais apresentando-1hes os objetivos do estudo e indagando acerca do interesse em participar do mesmo. Esclareci que gostaria de entender melhor o fenômeno em questão e indaguei-lhes se gostariam de colaborar, informando-lhes que seus depoimentos teriam caráter confidencial, sem necessidade de identificação.

Havendo anuência de todas, as entrevistas foram realizadas e os depoimentos gravados em fita magnética, com o prévio consentimento de cada uma, o que permitiu conferir a fidedignidade das informações obtidas, que foram analisadas com base nos estudos de MARTINS e BICUDO (1989).

\section{Merleau-Ponty e seu pensamento}

Maurice Merleau-Ponty é o representante francês da fenomenologia existencial, que busca compreender o homem em sua estrutura universal e, ao mesmo tempo na sua experiência concreta do vivido, ou seja compreender o homem em sua totalidade, engajado em um mundo, em uma realidade (CAPALBO, 1984).

Merleau-Ponty vê na fenomenologia a tarefa de elucidar as relações vividas e afetivas entre o homem e o mundo, valorizando o ENCONTRO entre as coisas e o EU, entre o EU e o OUTRO, relações estas mediatizadas pelo próprio corpo (CAPALBO, 1987). Assim sendo, a vertente existencial do referido autor é caracterizada pela tentativa de compreender o homem situado em um contexto, engajado em uma realidade, encarnado em um corpo, pertencente a um espaço histórico, social e político.

\section{Na visão de MERLEAU-PONTY (1971),}

(...) a percepção (...) é o fundo sobre o qual todos os atos se destacam e ela esta pressuposta por eles (...) o mundo é o meio natural e o campo de todos os meus pensamentos $e$ de todas as minhas percepções explicitas (...) o homem está no mundo e é no mundo que ele se conhece (...).

Deste modo, percebemos o mundo que nos cerca através de nosso corpo, estamos engajados em uma determinada realidade e não fugimos dela ao refletirmos. Somos um todo: um corpo sensivel que pensa, fala, comunica-se e interage com o meio, com seu mundo.

\section{ANÁLISE DOS DEPOIMENTOS}

Ser mulher, mãe e trabalhadora de enfermagem apresenta-se para estas mulheres como um momento desafiador assumindo conotações diferenciadas, como pode ser percebido nas Unidades de Significação extraídas de seus discursos.

\section{- Complicado conciliar casa/ trabalho/ filhos}

As depoentes acham complicado conciliar o mundo do trabalho (público) com o familiar (privado) em decorrência das inúmeras atividades que acumulam nas duas esferas. Os discursos que se seguem clarificam esta idéia:

"Ser mãe e trabalhar fora é a parte mais complicada porque a gente não trabalha só fora. Tenho babá, o que me ajuda com meu filho; mas a gente acaba trabalhando aqui e lá (em casa)" (Mariana)*

"É difícil conciliar o trabalho de casa com o da rua e principalmente criar filho. Você não consegue acompanhar totalmente os estudos, os amigos. Você sempre perde alguma coisa. É diferente do homem" ( Gabriele)

"É um peso enorme. É uma carga assim (...) você tem que dar conta como todas as mulheres que trabalham fora sempre têm uma sobrecarga maior do que os homens para chegar em, casa, trabalho de casa, filhos, marido, rotina de casa (...)" (Sonia)

"É um desafio. Tenho dois filhos pequenos e tenho que dividir a atenção entre as crianças, o trabalho e o marido. As vezes ele não entende, quer a gente mais presente, ai fica complicado" (Bruna)

Os discursos evidenciam a dificuldade em conciliar os diversos papéis assumidos pela mulher que, na esfera privada, já é sobrecarregada com seus afazeres, com a rotina doméstica que absorve o seu cotidiano porque tudo o que ocorre na casa requer sua atenção, sua participação direta, seu envolvimento. E, na esfera pública, assume como os demais trabalhadores, suas atribuições de rotina; entretanto, sua entrada no mercado de trabalho não a desvincula, necessariamente, de suas atribuições domésticas, contribuindo para a sobrecarga de trabalho.

\footnotetext{
* O nome das depoentes é fictício.
}

Em alguns depoimentos é clara a diferenciação entre os sexos no tocante às esferas de atuação pública 
$\mathrm{X}$ privada, sendo também exigido das mulheres sua participação enquanto esposa, dedicando ao companheiro momentos de carinho e atenção.

O cansaço com a dupla jornada é referido por algumas mulheres como fator que, muitas vezes, interfere em suas opções na vida do trabalho (a busca de novas oportunidades) e familiar (a escolha do número de filhos). Alegam que a sobrecarga maior de responsabilidade sobre os filhos e as rotinas domésticas ainda recaem sobre ela.

\section{- Limitações para progredir profissionalmente}

Nos recortes de depoimentos, abaixo citados, é externada pelas mulheres a nítida sensação dos limites na busca do progresso profissional em decorrência das responsabilidades com os filhos e com as atribuições familiares:

"Sinto-me mais limitada porque não posso fazer cursos (...) tenho que dedicar o tempo que sobra para dar atenção ao meu filho. Trabalhar fora e ter filhos limita (...) não estudo, quando saio tento conciliar um passeio mais familiar (...) Limita, mas não impede. Tem certas coisas que não dá pra fazer mesmo" (Mariana)

"Queria estudar mais e não pude pela falta de tempo. Comecei a fazer um curso de pós-graduação mas o horário era aos sábados ou à noite. Optei pelos sábados, ai começaram os problemas porque eram todos os sábados o dia todo. E aî? Quem fica com as crianças? No começo, meu marido ficava, mas depois começaram os problemas e eu acabei abandonando o curso (...). Viajar para Congressos, plantão, pós-graduação (...) eles (os homens) arranjam tempo para tudo (...) a mulher fica sobrecarregada. Você quer se atualizar e não pode. Você abre mão pelos filhos, dá um freio porque acha que vai prejudicar (...)" (Marisa)

Os depoimentos enfocam bem a idéia de que ser mulher é sinônimo de doação, de dedicação ao marido, aos filhos, à família. Nem sempre estes momentos são compartilhados. Muitas vezes são de grande solidão, de frustração causada pela desistência de oportunidades no campo profissional ou de qualificação para atender a demanda de um mercado de trabalho cada vez mais competitivo... Enfim, são momentos de escolhas dificeis em que nem sempre podem optar pelo que realmente gostariam de fazer, na maior parte das vezes pressionadas pela própria conjuntura familiar.

\section{- Dificuldade para acompanhar o crescimento dos filhos}

As depoentes relataram a dificuldade em conciliar o crescimento dos filhos com a atividade profissional:

"(...) acompanhar o crescimento da criança (...) isso você perde. A mulher só deveria trabalhar depois que o filho crescesse porque você perde os pequenos gestos, o crescer. Você começa a viver do passado, como eles eram (...) "(Gabriele)

"Você não vê os filhos crescerem como as demais, acompanhar o processo. E um risco, se você quer independência (...) Trabalhar fora (...) o que interfere é não dar assistência ao filho, à casa. "( Sonia)

Nestes depoimentos ficou claro que as mulheres se ressentem pela "sensação de perda" do acompanhar o crescimento/amadurecimento dos filhos. No relato de Gabriele, a prioridade para a mulher deveria ser a família, os filhos e, posteriormente, a realização profissional. Acompanhar o processo de crescimento dos filhos torna-se fundamental à medida que revela a importância do aspecto afetivo na vida das mulheres. Seu filho é uma parte sua , na maioria das vezes amado e desejado, que necessita da atenção e do "olhar atentivo" da mãe, da sua sensibilidade, do seu companheirismo, enfim da sua presença! E o mercado de trabalho contribui de maneira significativa para o afastamento das mulheres trabalhadoras do "convivio familiar tradicional".

Muitas depoentes referiram que estar inserida no mercado de trabalho torna-se mais complicado ainda quando os filhos são pequenos. O retorno às atividades profissionais é doloroso (após a licença maternidade); às vezes, é necessário conseguir quem cuide de seu bebê enquanto você trabalha; muitas apóiam-se em outras mulheres (como as avós, tias, babás) para auxiliá-las, ou recorrem às creches (que em muitas situações, tornase um processo muito dispendioso, decisivo para o retorno ou não às atividades profissionais).

\section{- A Enfermagem facilita a tomada de decisões em familia}

As depoentes referiram que atuar na área de enfermagem facilita nas decisões em relação ao aspecto de saúde da família:

"É vantagem ser enfermeira para lidar em casa, para tomar iniciativa com problemas de saúde em casa; diferente das demais mulheres que ficam indecisas, sem saber o que fazer com o filho doente. Tenho mais autonomia para 
agir. O marido me deixa agir porque sabe que eu sei o que fazer." (Sonia)

"A experiência na área da saúde, paciência, entrosamento com ser humano ajudam muito em casa para criar os filhos." (Marisa)

A mulher da área de enfermagem valoriza sua profissão acreditando que facilita no seu relacionamento familiar, bem como na tomada de decisões em caso de adoecimentos. Sente-se mais preparada para o próprio cuidado com os filhos, a partir de sua experiência profissional, principalmente se atua na área materno-infantil. As profissionais acreditam, também, que o trabalho em turnos, característico na área, ajude na conciliação da vida pública com a vida privada, apesar de sentirem dificuldade nos finais de semana e feriados quando é mais complicado conseguir quem fique cuidando dos filhos.

\section{- O trabalho contribui para o respeito e valorização da mulher}

Estar inserida no mercado de trabalho é fator de orgulho para as mulheres, que se sentem valorizadas e respeitadas. Os discursos que se seguem clarificam este aspecto:

"Trabalhar fora possibilita à mulher poder dar alguma coisa (...) Hoje a mulher tomou outro rumo na vida. Sua independência faz com que seja respeitada. Sai para trabalhar, se realiza como pessoa e como ser humano. Com todas as dificuldades (...)."(Vera)

"Ser mulher é gratificante. Trabalhar fora, ter sua profissão (...) só em casa falta algo (...) mulher tem que participar, trabalhar mais, é o progresso (...)." ( Gabriele)

A mulher - profissional de enfermagem ou de qualquer outra área - sente-se prestigiada pelo fato de "trabalhar fora". Receber salário (mesmo não sendo o idealizado) pelos serviços prestados, ter autonomia e independência financeira são fatores significantes para essas mulheres, denotando liberdade de escolha, possibilidade de comando e direito à voz. Deixar o ambiente doméstico (privado) para compor a massa trabalhadora, mesmo com todas as dificuldades inerentes a esta opção, não desestimula aquelas que visualizam a importância de serem trabalhadoras e exercerem a sua "independência"

Estas unidades de significação revelam que a mulher continuamente interage com o meio no qual está inserida, sofre interferências do ambiente em que vive $\mathrm{e}$ as reproduz em seu cotidiano. Nestas afirmaçõeslembramos MERLEAU-PONTY(1971) : " (...) por meu campo perceptivo , com seus horizontes espaciais estou presente em meu meio...por meu campo perceptivo, com seus horizontes temporais, estou presente em meu presente, em todo passado que o precedeu e num futuro (...) " Assim sendo percebemos o mundo que nos cerca com nosso corpo, com nossa presença. Reflete-se em nossas ações nossa visão de mundo, nossa percepção daquilo que vivenciamos.

\section{CONSIDERAÇÕES FINAIS}

A vivência de ser mãe e profissional de saúde suscitou em mim sensações que culminaram com a realização deste estudo. Os múltiplos papéis assumidos pela maioria das mulheres que exercem uma atividade profissional tendem a remetê-las a determinadas situações em que se sentem impotentes e frustradas por não conseguirem conciliar seus inúmeros afazeres. A sobrecarga de trabalho, com jornadas duplas ou triplas pode conduzir a mulher ao stress emocional, considerando que sua inserção no mercado de trabalho não a desvinculou das "tarefas domésticas" e da educação dos filhos, resultando num acúmulo de atribuições.

A realidade das trabalhadores de enfermagem que no trabalho convivem rotineiramente com a dor e o sofrimento, precisando ocultar seus sentimentos e externar ações de calor humano, compreensão e afetividade inquietou-me, remetendo-me à possibilidade da realização deste estudo. Ser mulher, mãe e trabalhadora de enfermagem comporta uma série de emoções, sensações só conhecidas por aquelas que convivem com esta realidade.

Em relação à enfermagem, fazer parte de um grupo de trabalhadoras de uma profissão essencialmente feminina traz em seu bojo características peculiares ao gênero. Entretanto, não foi revelado pelas depoentes que este tipo de trabalho interfere de maneira negativa no seu cotidiano em decorrência das particularidades da área. Para elas, "trabalhar fora" é o que complica, independen-temente da natureza do trabalho, e em decorrência de toda uma estrutura familiar arraigada em nossa sociedade.

Ser mulher, mãe e trabalhadora de enfermagem é um desafio para essas mulheres que sentem, continuamente, o peso da responsabilidade assumida, mesmo que involuntariamente. Assim, muitas comportam-se como Nina, ao revelar: "Tento ser mulher, profissional e mãe (...) mas é dificil, você se sente impotente (...) tive que aprender a lidar com as dificuldades (...) é difícil mas é superável (...) não é como eu queria. Você precisa viver, manter seu casamento, direcionar seu trabalho. A mulher é mais batalhadora, é mais capaz". 
A capacidade de transpor os obstáculos do diaa-dia vivido pelas mulheres em foco denota a força e a perseverança dos "dóceis corpos" femininos (LOYOLA,1988). Ser mulher, mãe e trabalhadora de enfermagem é, portanto, a superação diária das "dificuldades" impostas pela vida, um desafio constante para o gênero, uma sucessão de sentimentos e sensações que permeiam o viver de cada uma, delineando e revelando suas histórias de vida.

Apesar das dificuldades, ou talvez por causa delas, há que se ressaltar o esforço de todas na luta diária empreendida em prol do status social obtido no decorrer do tempo, garantindo com seu trabalho a possibilidade de independência, de uma vida melhor, de sua afirmação pessoal e profissional, e de exercer os direitos inalienáveis que todo ser humano tem ao trabalho, lazer, saúde... Deste modo, ser mulher, mãe e trabalhadora de enfermagem é conviver diariamente com as diferenças, os desafios... resistindo e revelando suas potencialidades.

\section{REFERÊNCIAS BIBLIOGRÁFICAS}

AVENDANO, C.; GRAU, P.; YUS, P. Riscos para a saúde das enfermeiras do setor público no Chile. In: BRETAS, A.C.P. Trabalho, saúde e gênero: na era da globalização. Goiânia, AB, 1997. p. 115-33.

CAPALBO, C. Alternativas metodológicas da pesquisa. In: SEMINÁRIO NACIONAL DE PESQUISA EM ENFERMAGEM, $3^{\circ}$, Florianópolis, 1984. Anais. Florianópolis, UFSC, 1984. p.130-57.

. Fenomenologia e Ciências Humanas. Rio de Janeiro, ERCA, 1987.

FONSECA, R.M.G.S. Espaço e gênero na compreensão do processo saúde-doença da mulher brasileira. Rev.Latino Am. Enf., v. 5, n. 1, p. 5-13, 1997.

LOYOLA, C.M.D. Os dóceis corpos do hospital: as enfermeiras e o poder institucional na

estrutura hospitalar. 2.ed. Rio de Janeiro, Editora UFRJ, 1988.

MARTINS, J.; BICUDO, M.A.V. A pesquisa qualitativa em psicologia: fundamentos e recursos

básicos. São Paulo, Moraes/EDUC, 1989.

MASSI, M. Vida de Mulheres - cotidiano e imaginário. Rio de Janeiro, IMAGO, 1992.

MERLEAU-PONTY, M. Fenomenologia da Percepção. Trad. Reginaldo di Piero. Rio de Janeiro, Freitas Bastos, 1971.
MOREIRA, M.C.N. Imagens no espelho de Vênus: mulher, enfermagem e modernidade. Rev. Latino Am. Enf., v. 7, n. 1, p. 55-65, 1999.

OLIVEIRA, B.G.R.B.; PEREIRA, A.L. Mulher = Enfermeira X Enfermeira $=$ Mulher. Eis a questão. Rev. Alt. Enf., v. 1, n. 4, p. 4-13, 1997.

SARTI, C.A. Os filhos dos trabalhadores: quem cuida das crianças? In: BRETAS, A.C.P. Trabalho, saúde e gênero: na era da globalização. Goiânia, AB, 1997. p. 51-60.

SCHIRMER, J. Trabalho e maternidade: qual o custo para as mulheres? In: BRETAS, A.C.P. Trabalho, saúde e gênero: na era da globalização. Goiânia, AB, 1997. p. 101-13.

SOBRAL, V.R.S. A purgação do desejo: memórias de enfermeiras. Rio de Janeiro, 1994. 149p. Tese (Doutorado) Escola de Enfermagem Anna Nery, Universidade Federal do Rio de Janeiro.

WALDOW, V.R. A opressão na enfermagem: um estudo exploratório. In: LOPES, M.J.M; MEYER, D.E.; WALDOW, V.R. Gênero e Saúde. Porto Alegre, Artes Médicas, 1996. p.106-32. 